\title{
Research on the Influence of Corporate Social Capital on Cash Flow Risk \\ Li Ling ${ }^{1, a}$, Yang Qian ${ }^{2,}$, ,
}

${ }^{1}$ Xi'an University of Science and Technology, Beilin District, Xian, Shaanxi, China

${ }^{2}$ Xi'an University of Science and Technology, Beilin District, Xi'an, Shaanxi, China

a233449957@qq.com, b514909181@qq.com

Keywords: Product market competition, Cash flow risk, Financing constraints

\begin{abstract}
The stable output of cash flow is an important indicator to measure the business conditions of enterprises, and it is also an important guarantee for promoting the growth of enterprises and improving market competitiveness. This paper takes China's A stock as a sample, introduces the degree of product market competition as the adjustment variable, and focuses on the social capital's influence on the company's cash flow risk. The empirical test found that the greater the corporate finance, political and social capital, the smaller the cash flow risk; the degree of product market competition plays a negative regulatory effect in the process of corporate social capital affecting cash flow risk.
\end{abstract}

\section{企业社会资本对现金流风险的影响研究 \\ 李玲 1 , a, 杨倩2, b \\ 1 西安科技大学, 碑林区, 西安, 陕西, 中国 \\ 2 西安科技大学, 碑林区, 西安, 陕西, 中国

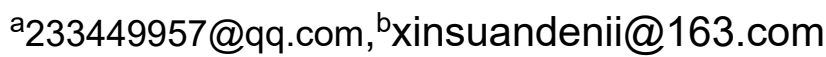

关键词: 产品市场竞争; 现金流风险; 融资约束

中文摘要. 现金流的稳定输出是衡量企业经营状况的重要指标, 也是促进企业成长、提高市 场竞争力的重要保障。本文以我国A股为样本, 引入产品市场竞争程度作为调节变量, 重点 论述了社会资本对于企业现金流风险所具有的影响能力。实证检验发现：企业金融、政治社 会资本越大，现金流风险越小; 产品市场竞争程度在企业社会资本影响现金流风险的过程中 发挥着负向调节效应。

\section{1. 引言}

企业日常经营和投资、融资活动中，现金流的影响能力都是不言而喻的，是评估企业抗 风险能力重要评价指标, 其大小及波动影响财务危机发生的概率, 对企业的生存发展至关重 要。在我国, 企业社会资本这一非正式制度是影响企业投融资的重要因素, 从企业社会资本 角度对公司现金流风险进行更为深入的研究和讨论，对于我们提升现金流信息披露的客观性 和真实性、优化利益相关者分析方案都有着重要的现实意义。

近年来有关企业社会资本对现金流的影响已成为学术界的研究热点。赵岩（2013）发现 企业社会资本对投资-现金流敏感性具有显著影响 ${ }^{11}$; 洪怡恬（2017）、陈德萍（2017）的研 究均表明社会资本与内部现金流敏感度密切相关 ${ }^{[2-3]}$ 。社会资本与现金流的交叉研究体现出国 
内外学者对现金流风险的高度关注，而公司现金流风险不仅受到财务制度的影响，还受市场 竞争对手的埽制。由 Tesler（1966）的掠夺理论（predation theory）认为现金持有量有助于公 司应对来自于产品市场竞争的风险 ${ }^{[4]}$ 。Hart (1983) 的研究表明产品市场竞争程度有利于公司 改善内部治理, 提高经营绩效 ${ }^{[5]}$ 。Market Power 认为社会资本与企业的竞争力相辅相成, 进 而增强企业的市场权利、促进企业发展。通过分析相关文献, 可以看出企业社会资本、产品 市场竞争程度均对现金流有一定程度的影响。本文引入产品市场竞争程度作为调节变量, 重 点论述了社会资本对于企业现金流风险所具有的影响能力, 希望能为企业定位非正式制度、 开展风险管理提供了一定的理论参考。

\section{2. 理论分析与研究假设}

\section{1企业社会资本对现金流的影响}

企业在选择战略、做出决策时不仅需要衡量内部经营管理水平, 更要关注从外部资本获 取资源的能力。陈晓芸 (2013) 发现社会资本能够抑制内部人对现金流滥用进而缓解过度投 资行为 ${ }^{[6]}$; 陈德萍从社会嵌入性视角研究了企业社会资本对企业融资约束的影响, 结果表明 企业社会资本能缓解现金流风险。

企业能否获得稳定的资金来源、及时足额筹集到生产经营所需要的资金, 对挑战新市场、 抓住新机遇都至关重要, 而银行贷款是外部融资的重要来源之一, 能够拥有银行资源是企业 良好发展的开端。宋一蓓研究表明银行授信能缓解融资约束 ${ }^{[7]}$; 吕敏蓉以中小板企业为研究 对象, 也证实了建立银企关系能减轻企业融资压力。因此在一定程度下, 拥有更多关系银行 和有金融从业背景高管的企业, 在与金融机构的互动中, 更容易获得经济上的支持, 缓解现 金流风险。企业不可能单独的存在于市场中, 一个公司长久稳定的发展必定依赖于上下游企 业的密切配合与运营，供应商提供优质的产品服务以及客户交易资金的及时回笼是企业现金 流稳定的重要保障, 更是增强产品市场竞争力的重要渠道。在我国当前阶段市场经济转型期 的大背景下, 我国各地方政府掌握着对于企业发展至关重要的各种稀缺资源, 手中握有的信 息对企业的发展很可能起到转折性的帮助, 因此从政府手中拿到的补信息及贴在一定程度上 影响着企业现金流量。王珍义（2016）等通过实证分析均指出上市公司政治关联与现金持有 水平具有显著的正相关关系 ${ }^{[8]}$ 。据此，本文提出假设 H1a、H1b、H1c：

H1a：企业金融社会资本与现金流风险负相关;

$\mathrm{H} 1 b$ : 企业市场社会资本与现金流风险负相关;

H1c：企业政治社会资本与现金流风险负相关。

\section{2 产品市场竞争程度对企业社会资本作用于现金流风险的调节效应分析}

Froot 等 (1993) 提出, 融资不足而给企业现金流所带来的风险, 集中体现在投资项目 和竞争对手之间的依赖关系上 ${ }^{[9]}$, 而这也是本文立论的根本出发点和落脚点。孙进军 (2012) 发现我国上市公司也会出于预防投资不足所导致的投资机会丧失以及市场份额被竞争对手占 有的掠夺风险而持有更多的现金 ${ }^{[10]}$ 。如果企业处于垄断或半垄断行业中，很容易因竞争对手 采取低价竞争、兼并合作商等掠夺策略而损失市场, 所以企业的产品市场竞争程度较大时, 企业一般倾向于持有更多现金。而当企业持有的现金量增多时，便不惧怕因为短暂的负债而 招致竞争对手的攻击, 因此现金流风险程度降低。而企业产品市场竞争程度没那么大时, 公 司为了产品能够被市场认同, 必定会从长远考虑, 制定出一系列的营销战略、品牌战略、资 源开发战略等来保证公司绩效快速增长, 这时良好的企业社会资本便成为重要的战略要素之 一。因此对于产品市场竞争较小的企业来说, 在经营过程中可以随时以合理的成本获得相应 的资金, 融资和投放之间关系的调整, 可平衡现金的流入和流出, 所以企业的现金流风险相 对较小。根据以上分析, 本文提出假设 $\mathrm{H} 2 \mathrm{a} 、 \mathrm{H} 2 \mathrm{~b} 、 \mathrm{H} 2 \mathrm{c}$ : 
$\mathrm{H} 2 \mathrm{a}$ ：现金流和金融社会资本之间的关系，受到市场竞争程度的负向调节。

$\mathrm{H} 2 b$ ：现金流和市场社会资本之间的关系，受到市场竞争程度的负向调节。

$\mathrm{H} 2 \mathrm{c}$ ：现金流和整治社会资本之间的关系，受到市场竞争程度的负向调节。

\section{3. 研究设计}

\section{1 样本选择与数据来源}

在本文研究中，以 A 股上市公司 2014 2016 年的公开数据作为样本。同时按以下标准 对样本进行进一步的篮选：(1)剔除金融保险行业; (2)剔除 ST 及*ST 企业; (3)剔除数据不完 整企业。最后共得到 2983 组样本数据。文中金融、政治社会资本部分指标由上市公司年报搜 集整理, 其余数据来自 CSMAR 数据库和 WIND 数据库, 并使用 Excel11.0 和 SPSS19.0 对 数据进行处理和回归检验。

\section{2 模型与变量}

\subsection{1 模型构建}

本文采用实证回归方法对提出的假设进行验证。建设模型(1)(2)(3)对进行检验, 模型 (4)(5)(6)对假设 H2a、H2b、H2c 进行检验:

$$
\begin{gathered}
\text { Crsh }=\alpha 1+\alpha 2 \text { Fcap }+\alpha 3 \text { Scal }+\alpha 4 \text { Natu }+\alpha 5 \text { Real }+\alpha 6 \text { Prof }+\varepsilon 1 \\
\text { Crsh }=\beta 1+\beta 2 \text { Mcap }+\beta 3 \text { Scal }+\beta 4 \text { Natu }+\beta 5 \text { Real }+\beta 6 \text { Prof }+\varepsilon 2 \\
\text { Crsh }=\gamma 1+\gamma 2 \text { Scap }+\gamma 3 \text { Scal }+\gamma 4 \text { Natu }+\gamma 5 \text { Real }+\gamma 6 \text { Prof }+\varepsilon 3 \\
\text { Crsh }=\delta 1+\delta 2 \text { Fcap }+\delta 3 \text { Comp } * \text { Fcap }+\delta 4 \text { Scal }+\delta 5 \text { Natu }+\delta 6 \text { Real }+\delta 7 \text { Prof }+\varepsilon 4 \\
\text { Crsh }=\zeta 1+\zeta 2 \text { Mcap }+\zeta 3 \text { Comp } * \text { Mcap }+\zeta 4 \text { Scal }+\zeta 5 \text { Natu }+\zeta 6 \text { Real }+\zeta 7 \text { Prof }+\varepsilon 5 \\
\text { Crsh }=\theta 1+\theta 2 \text { Scap }+\theta 3 \text { Comp } * \text { Scap }+\theta 4 \text { Scal }+\theta 5 \text { Natu }+\theta 6 \text { Real }+\theta 7 \text { Prof }+\varepsilon 6
\end{gathered}
$$

模型(1)、(2)、(3)中，当 $\alpha_{2} 、 \beta_{2} 、 \gamma_{2}$ 远小于零时，假设 H1a、H1b、H1c 成立，企业金融、 市场、政治社会资本与现金流风险负相关。模型(4)、(5)、(6)中，当 $\delta_{3} 、 \zeta_{3} 、 \theta_{3}$ 远大于零时， 假设 H2a、H 2 b、H 2 c 成立, 产品市场竞争程度对企业金融、市场、政治社会资本这几大因素 与现金流风险之间的相关性的影响为负面的。

\subsection{2 变量定义}

a) 企业社会资本

边燕杰、丘海雄用三个指标测量企业社会资本，包括企业法人代表是否在上级领导机关 任过职、是否跨行业出任过领导职务等, 该测度方法主要针对法人, 并不能完全涵盖企业社 会资本; 本文主要借鉴李辉的方法梳理社会资本维度, 将社会资本划为三类, 分别是企业金 融、市场及政治社会资本, 各个维度的社会资本均采用上市公司公开财务指标测度, 运用系 数突变法合成三类自变量。

b) 现金流风险

目前，也有一些专家和学者以现金流标准差、方差的形式为基础研究现金流风险对企业 经营的影响、防范现金流风险的具体对策等。范圣然借鉴 Richard 的做法, 认为连续三年投 资净现金流标准差即为现金流风险; 本文采用现金净流量波动性定义现金流风险。因为这种 界定方式不仅可以更好的体现出现金流风险和企业竞争行为之间的关系，同时 “波动性” 具 有正向波动和负向波动两种情况, 更为贴合企业的实际经营状态。为了保证所选择的指标可 以直观的展现出现金流波动性的概念, 本文选择了企业非流动资产的标准差中连续三年经营 现金流量净额所占比例的方式，从而有效的控制规模偏差所导致的计算结果精度不足的问题。

c) 产品市场竞争程度 
对于产品市场竞争程度的测度, 大部分学者偏好采用诸如行业集中度（CRn）或赫芬达 尔指数 (Herfindahl-Hirschman Index) 等指标, 也同样有部分专家学者认为绩效指标可更好的 反映出产品的实际市场竞争力。Nickell（1996）提出的主营业务利润率对我国市场更为具有 指导意义，这一指标实际上是指产品市场的垄断性与企业的 “垄断租金” 变化一致，而 “垄 断租金” 较低则意味着产品市场竞争较高。本文采用主营业务利润率作为产品市场竞争程度 的度量指标, 但考虑到许多企业在成本管控方面可能不是很娴熟, 在产品市场竞争程度不大 的情况下也不一定取得最大利润，所以最终使用经营活动产生的现金流量净额比营业收入衡 量产品市场竞争程度, 该方法在实际的应用过程中可以尽量规避内部成本对市场竞争程度造 成的影响, 该指标越小, 表明产品市场竞争程度越大。

表1 变量名称和计算方法

\begin{tabular}{c|cc}
\hline 变量名称 & 变量含义 & 计算方法 \\
\hline 被解释变量 & 现金流风险 Crsh & $\mathrm{t}-2$ 至 $\mathrm{t}$ 年[经营性现金流量净额/(资产总额-交易性金融资产-货币资 \\
& 金)] 的标准差 \\
\hline \multirow{4}{*}{ 解释变量 } & 金融社会资本 Fcap & 信用借款/短期借款 \\
\cline { 2 - 3 } & 市场社会资本 Mcap & 前十大股东中是否含金融机构 \\
\cline { 2 - 3 } & 政治社会资本 Scap & 应付账款周转率 \\
& 应收账款周转率 \\
\hline 调节变量 & 市场竞争程度 Comp & 政府补助的自然对数 \\
\hline \multirow{3}{*}{ 控制变量 } & 企业规模 Scal & 企业家是否曾担任人大代表或政协委员 \\
\cline { 2 - 3 } & 变现能力 Real & 经营活动产生的现金流量净额/营业收入 \\
\cline { 2 - 3 } & 盈利能力 Prof & 企业资产总额的自然对数 \\
\hline
\end{tabular}

d) 控制变量

企业规模较大时，比较倾向于拿出一部分资产做长短期投资，具有变现能力的资产多于 中小企业，所以其现金流风险较小; 当实际控制人为国企时，更容易获得国家财政的补贴支 持，这在很大程度上保障了现金流的稳定持续; 具有较多流动资产的企业在现金不足时，能 因变现资产获得更多现金; 一般情况下盈利能力较强的企业，因经营活动获得的现金流净额 更多，大大降低了发生现金流风险的概率。因此本文选取了企业规模、实际控制人性质、流 动比率、总资产报酬率四个指标作为控制变量。变量及其计算方法如表 1 所示。

\section{4. 实证结果分析}

\section{1 描述性统计分析}

表 2 回归数据的描述性统计

\begin{tabular}{ccccccc}
\hline 变量 & 观测值 & 均值 & 标准差 & 极小值 & 中位数 & 极大值 \\
\hline Crsh & 2983 & 0.0558 & 0.0491 & 0.0028 & 0.0403 & 0.3019 \\
\hline Fcap & 2983 & 0.5585 & 0.4477 & 0.0000 & 0.4759 & 4.6164 \\
\hline Mcap & 2983 & 11.8142 & 16.2578 & 0.6967 & 5.5446 & 97.1866 \\
\hline Scap & 2983 & 1.1048 & 0.5795 & 0.5534 & 0.8470 & 2.8824 \\
\hline Comp & 2983 & -0.0396 & 1.2671 & -6.9151 & 0.0428 & 0.9207 \\
\hline
\end{tabular}

从表 2 的描述性统计结果来看, 被解释变量现金流风险（Crsh）的中位数与均值相差不 大, 说明所选样本企业现金流风险存在差距较小, 差异主要由极值引起; 金融社会资本的均 值为 0.5585 , 标准差为 0.4477 ; 市场社会资本的均值为 11.8142 , 标准差为 16.2578 ; 政治社 会资本的均值为 1.1048 , 标准差为 0.5795 , 说明 A 股中各个企业的社会资本的发展水平存在 
一定的差距，其中各企业间的金融社会资本差距最大，市场社会资本差距其次，政治社会资 本差距最小。产品市场竞争的均值为 -0.0396 , 即在总营业收入中, 净现金流所占平均比重为 $-3.96 \%$, 同时产品市场竞争极大值为 $92.07 \%$, 极小值为 $-691.51 \%$ 。这一数据证明目标公司产 品市场竞争性在不同样本数据中的差异可能非常巨大。

\section{2 相关性分析}

表 3 社会资本、现金流风险产品市场竞争程度之间的相关性

\begin{tabular}{cccccc}
\hline 变量 & Crsh & Fcap & Mcap & Scap & Comp \\
\hline Crsh & 1 & & & & \\
\hline Fcap & $-.202^{* *}$ & 1 & & & \\
\hline Mcap & .011 & -.031 & 1 & & \\
\hline Scap & $-.152^{*}$ & -.141 & .119 & 1 & \\
\hline Comp & $-.385^{* *}$ & -.095 & .009 & .025 & 1 \\
\hline *分别表示在 $1 \%, 5 \%$ 水平上显著 & & & &
\end{tabular}

用 SPSS19.0 的多元回归分析法进行假设检验之前, 为确定回归分析模型能够进行假设检 验, 对解释变量、被解释变量以及调节变量之间做相关性分析, 结果如表 3 所示。可以看出, 解释变量以及调节变量与被解释变量之间存在相关性, 并且三个解释变量和调节变量之间互 相均不存在相关性。即金融、政治社会资本以及产品市场竞争程度与现金流风险在 5\%水平上 高度相关，金融、市场、政治社会资本与产品市场竞争程度各不相关。因此，可以对模型进 行假设检验。

\section{3 回归结果分析}

企业社会资本、产品市场竞争程度及现金流风险的回归结果如表 4 所示。序列相关问题 则以 Durbin-Waston 值检测，多重共线性问题采用方差膨胀因子（VIF）指数加以处理。结果 表明，各模型的 DW 值介于 $1.8 \sim 2.0$ 之间，不存在序列相关问题。主效应在结果分析中不一 定是显著的, 如果交互项对因变量有显著回归系数, 那么同样不能否定证明调节效应的存在。

表 4 社会资本对现金流风险的多元回归结果

\begin{tabular}{ccccccc}
\hline 变量 & 模型 1 & 模型 2 & 模型 3 & 模型 4 & 模型 5 & 模型 6 \\
\hline 常数项 & $.183^{* *}$ & $.226^{* *}$ & $.186^{* *}$ & $.180^{* *}$ & $.258^{* *}$ & $.213^{* *}$ \\
\hline Fcap & $-.018^{* *}$ & & & $-.016^{*}$ & & \\
\hline Mcap & & -.001 & & & -.001 & \\
\hline Scap & & & $-.016^{* *}$ & & & $-.012^{*}$ \\
\hline Comp*Fcap & & & & $-.070^{* *}$ & & \\
\hline Comp*Mcap & & & & & $-.002^{* *}$ & \\
\hline Comp*Scap & & & & & & $-.018^{* *}$ \\
\hline Scal & $-.005^{*}$ & $-.007^{* *}$ & -.004 & $-.005^{*}$ & $-.008^{* *}$ & $-.006^{* *}$ \\
\hline Natu & $-.003^{*}$ & $-.008^{*}$ & $-.017^{* *}$ & .001 & $-.006^{*}$ & -.010 \\
\hline Real & -.001 & -.001 & -.001 & -.001 & -.004 & -.003 \\
\hline Prof & .014 & .004 & .005 & .078 & .080 & .071 \\
\hline Adj_R & 0.044 & 0.032 & 0.052 & 0.062 & 0.134 & 0.194 \\
\hline F & 2.678 & 2.198 & 3.011 & 3.016 & 5.732 & 8.333 \\
\hline DW & 1.951 & 1.909 & 1.968 & 1.975 & 1.879 & 1.919 \\
\hline
\end{tabular}

$* *, *$ 分别表示在 $1 \%, 5 \%$ 水平上显著

表 4 中模型 1、2、3 分别论证了企业金融、市场、政治社会资本对现金流风险的影响程 度，模型 4、5、6 分别论证了产品市场竞争程度对企业金融、市场、政治社会资本与现金流 风险关系的调节作用。从表中可以看出，各组数据的 $\mathrm{Adj}_{-} \mathrm{R}^{2}$ 各自不同，说明影响企业现金流 风险的因素很多，并且影响程度各不相同；企业金融、政治社会资本与现金流风险的相关性 分别在 $5 \%$ 水平上显著，而企业市场社会资本与现金流风险不相关，假设 H1a 和 H1c 成立。 这也验证了我国 $\mathrm{A}$ 股上市公司在销货与回款方面对现金流风险的影响较小，主要还是依赖其 
所拥有的金融社会资本和政治社会资本，进而影响企业现金流的波动性。

模型 4、5、6 分别是在模型 $1 、 2 、 3$ 的基础上加入了产品市场竞争程度作为调节变量, 可以看出 Adj_R ${ }^{2}$ 增大了, 说明在加入调节变量后, 方程拟合度得到提升, 同时产品市场竞争 程度*金融社会资本、产品市场竞争程度*市场社会资本、产品市场竞争程度*政治社会资本与 现金流风险均在 $5 \%$ 水平上相关, 由此可以证明, 产品市场竞争程度较低时, 企业金融、市场、 政治社会资本与现金流风险的相关性得到负向调节，假设 H2 成立。

\section{5. 结论与建议}

在我国资本市场中, 产品竞争异常激烈, 而对于产品市场竞争程度较小的企业, 不需要 持有过多数量的现金来预防竞争对手的掠夺策略，因而为了企业发展，更倾向于运用目前所 拥有的各种社会资本，增加企业绩效，完善企业的现金流管理。而要从有限的资源中获取日 常经营所需的各种资源，在自身实力充足的情况下，一定的社会资本是必不可少的，与金融 机构的良好合作以及与政府的友好关系，都能够缓解企业的现金流风险。所以企业在注重内 部管理的同时, 可以加强与银行的账款往来以降低信息不对称度, 增强银行对企业的信任; 或者适当承担一定的社会责任以赢得政府的好感。

\section{致谢}

本文为国家社科基金一般项目 《陕西经济创新驱动发展的实现方式研究》(14JK1446)的 阶段性成果之一。

\section{References}

[1]Zhao Yan. Corporate Social Capital, Financing Constraints and Investment: A Study of Cash Flow Sensitivity [J]. Journal of Hunan University of Finance and Economics, 2013, 29(02): $77-84$.

[2] Hong Yitian. Analysis of the Influence of Social Capital on Financing Constraints of Logistics Related Enterprises [J]. Statistics and Decision, 2017, (18): 182-185.

[3] Chen Deping, Zhang Wenling. Empirical Analysis of Corporate Social Capital and Financing Constraints [J]. Statistics and Decision, 2017, (07): 186-188.

[4]Tesler, L.G..,1966, “Cutthroat Competition and the Long Purse”,Journal of Law and Economics,9,pp.259-277.

[5]Hart O.The Market as an Incentive Mechanism[J].Bell Journal of Economics,1983 (14):366-382.

[6] Chen Xiaoyun, Wu Chaopeng. Political relations, social capital and corporate investment efficiency: An analysis based on the perspective of investment-cash flow sensitivity [J]. Journal of Shanxi University of Finance and Economics, 2013, 35(06): 91-101.

[7] Song Yibei. Empirical Analysis of the Impact of Government-Enterprise Relations and Credit Lines on Investment-Cash Flow Sensitivity [J]. Statistics and Decision, 2016, (04): 166-169.

[8] Wang Zhenyi, He Qiutong, Xie Meng, He Huqin. Executives' political connections and over-investment in enterprises: Using free cash flow as an intermediary effect[J]. Investment Research, 2016, 35(07): 99-108.

[9]Froot, K., Scharfstein D., Stein J. Risk Management Coordinating Corporate Investment and Financing Policies[J]. Journal of Finance, 1993,48(5):1629-1658 
[10] Sun Jinjun, Gu Naikang. Does the Product Market Competition Affect Corporate Cash Holdings?___An Empirical Study Based on Predation Theory [J]. Investment Research, 2012, 31(08):18-29. 